\title{
Personality Traits of Preschoolers as Subjects of Collaborative Thinking Activity
}

Belousova A.K.

Barsukova O.V.

Vyshkvyrkina M.A.

Kryschenko E.P.

Tushnova J.A.

Mochalova J.A.

Mozgovaya N.N.

\section{Doi:10.5901/mjss.2015.v6n5s1p79}

Pavlova T.V.

Abstract

Results of numerous studies in the national psychology demonstrate the decisive role of personality traits of the participants of collaborative thinking activity. Such studies had established the fact of the determining influence of personality traits of the participants on the collaborative thinking activity. In our study, we examined the personality traits of preschoolers as participants of collaborative thinking activity. The study allowed us to compose personality profiles of preschoolers on the basis of psychological typology of C. Jung, and also to study the personality traits of preschoolers, which can cause difficulties in communication (aggression, conflict, negativism, asociality, isolation).

Keywords: senior preschoolers, collaborative thinking activity, communication difficulties, personality traits of preschoolers as communication subjects in conditions of collaborative thinking activity.

\section{Introduction}

Transformations of a modern education system also affect the preschool education and lead to changes in its content and methodological components. The need of society for intelligent, competitive, competent professionals aiming for selfdevelopment and continuous personal and professional growth, puts special demands on the educational process. Today, the phenomena that occur in the collaborative thinking activity, characteristics of functional and role distribution, generation of common meanings, evaluations, characteristics of transfer and perception of meanings with ever more increasing frequency become the subject of psychological study. However, of particular importance is a profound and detailed study of the mechanisms of formation of collaborative thinking activity at preschool age. Of particular interest in this context is the study of the intellectual, personal, emotional, communicative characteristics of a modern preschooler. The collaborative thinking activity in this sense is a universal mechanism of multicenter study of collaborative thinking subjects from the standpoint of the individual and combined subjects.

In our study, collaborative thinking activity is presented as a self-organizing system, where its participants are the center of it (A.K. Belousova). From the point of view of the theory of collaborative thinking activity self-organization by A.K. Belousova, collaborative thinking activity can be represented as a system, in the unity of its constituent elements, levels and spheres. Considering the collaborative activity as a system one can distinguish its constituent elements or spheres: intellectual, communicative, cooperative and personal. Each of the selected spheres is of particular interest in the context of the general psychological analysis of the characteristics of the collaborative thinking activity of preschoolers. However, the results of numerous studies in the national psychology demonstrate the decisive role of the personality traits of the participants of collaborative thinking activity that form the personal sphere.

\section{Theoretical Framework}

The results of the numerous studies (Brushlinsky A.V., 1990, Kuchynsky G.M., 1981; Mastvilisker E.I., 1989; Oblasova 
O.V., 2002; Dautov D.F., 2009, etc.) show a decisive role of the personality traits of the collaborative thinking activity participants. So, G.M. Kuchynsky emphasized that "personalities communicate" (Kuchynsky G.M.,1981, P. 119), and personality traits of the participants (for example, personal motives) of the collaborative thinking activity determine the nature of communication in the process of the problem solving.

A.V. Brushlinsky in the pilot study of the group's work on the problem solving, found that the personal aspects of the interaction subjects (motives and needs of the cognitive activity, emotional sphere of a person) have an impact on the process of the problem solving (Brushlinsky A.V., 1990).

E.I. Mastvilisker pointed to the fact that the personal qualities of the collaborative thinking activity partners, along with other characteristics (e.g., temperament) affect the degree of tension in the communication (Mastvilisker E.I., 1989). Tension in the communication can significantly complicate the problem solving process, affecting the efficiency of the collaborative thinking activity.

N.R. Khusainova studied the personal determinants of the "withdrawals" from the thinking activity in the problem solving (Khusainova N.R., 1989). The researcher suggest that the personality traits have a decisive influence, on the one hand, on the level of the activity organization (standard, above standard and level of "withdrawals"), on the other hand on the semantic fields of the activity implementation.

O.V. Oblasova, D.F. Dautov, A.K. Belousova noted that the personality traits of the collaborative thinking activity partners determine the adoption of the role and function execution by the partners in solving the intellectual task (Oblasova O.V., 2002; Dautov D.F., Belousov A.K., 2009).

Summarizing the above-considered studies, it should be noted that many researchers have stated the fact of the determining influence of the participants' personality traits on the collaborative thinking activity, studying primarily the motivational aspects of the collaborative thinking activity (Kuchynsky G.M., Brushlinsky A.V., etc.), and personality traits of the collaborative thinking activity participants on the process of the intellectual problem solving (Khusainova N.R., Oblasova O.V., Mastvilisker E.I.). However, it should be emphasized that the study of the personality traits of the collaborative thinking activity participants is mainly carried out on adolescents, youths and adult subjects.

\section{Hypothesis}

The study of the intellectual, cooperative, communicative spheres of the collaborative thinking activity (Pavlova T.V., 2010; Pavlova T.V., Belousova A.K., 2013 ) of the preschoolers allowed to establish as facts the personality traits manifestations of the collaborative thinking activity participants that complicate the communication process and problem solving process. In this regard, an additional hypothesis was formulated: there are personal qualities of the preschoolers that affect the interpersonal communication in the process of the collaborative solving of the intellectual tasks. In order to verify the formulated hypothesis, we organized and conducted the additional study.

\section{Method}

To study the personality traits of the preschoolers we analyzed the drawings with $\mathrm{H}$. Read's scheme based on characterological traits. The content of the analyzed children's drawings fit into the drawing types, identified by H. Read. Classification of drawings by $\mathrm{H}$. Read's drawing types allowed to quantify the following personality types.

\section{Results}

As the table shows, most of the preschoolers have - introverted thinking (36.9\%) and extraverted thinking (19\%) personality types (Table 1.).

Table 1. Drawing types and corresponding personality types of preschoolers

\begin{tabular}{|c|l|l|c|c|}
\hline № & Drawing type & Personality type & Quality & $\%$ \\
\hline 1. & Emphatic & Extraverted sensation & 2 & 2,4 \\
\hline 2. & Haptic & Introverted sensation & 0 & 0 \\
\hline 3. & Rhythmic & Extraverted intuition & 14 & 16,7 \\
\hline 4. & Structural & Introverted intuition & 4 & 4,8 \\
\hline 5. & Organic & Introverted thinking & 31 & 36,9 \\
\hline 6. & Imaginary & Introverted feeling & 10 & 11,9 \\
\hline
\end{tabular}




\begin{tabular}{|c|l|l|c|c|}
\hline 7. & Decorative & Extraverted feeling & 7 & 8,3 \\
\hline 8. & Enumerative & Extraverted thinking & 16 & 19 \\
\hline
\end{tabular}

According to C. Jung's psychological typology, as noted by E.S. Romanova and O.F. Potemkina, thinking personality type (Romanova E.S., Potemkina O.F., 1992):

- focuses on the objective reality and its laws, which person always seeks to follow;

- likes to analyze and determine the logical order in everything;

- can be demanding for the good of the cause, while ignoring the feelings of others;

- proves one's right (right or wrong, reasonable or unreasonable);

- as a rule, it is difficult for him to talk about feelings, they are stable and change slowly;

- does not like to investigate the cause of quarrels and misunderstandings both one's own and others.

Unlike the introverted thinking, the extroverted thinking types are able to think positively, creating new facts, new theories. However, they tend to generalize a large number of the unrelated facts. For the introverted thinking types is characteristic the interest to gathering the facts to use them later in a discussion to prove their theoretical positions. It can be assumed that the dominance of the thinking types, including the introverted type among the preschoolers, is connected with the change of the leading type of activity in the senior preschool age. Education is becoming the leading activity.

It should be noted that in the test sample there are also represented the extroverted intuition (16.7 \%) and introverted feeling (11.9\%) personality types. For the extroverted intuition types is characteristic to rely not on thinking but intuition. For them, it is also characteristic to insist on their own morals, which may differ from the generally accepted. People with the introverted feeling personality type are most often silent, cold and indifferent to what is happening around, abstruse for the others (Figure 1.).

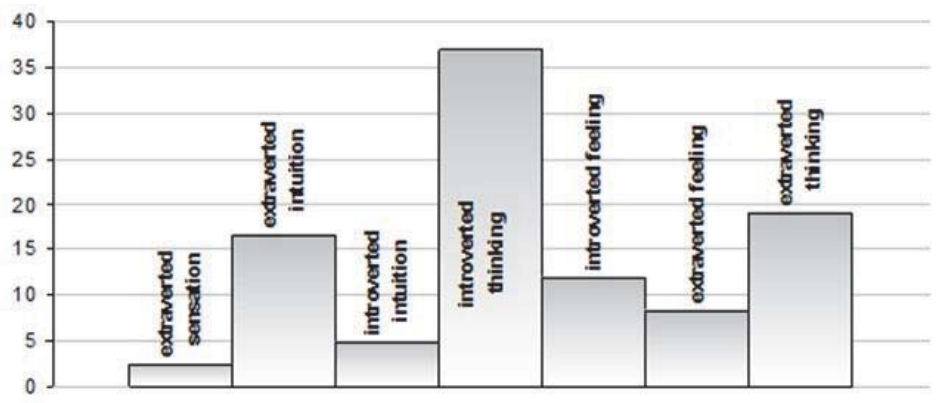

Figure 1: The representation of preschoolers' personality types (according to C. Jung)

\section{Discussion of Results}

Then we carried out the comparative analysis of the identified personality types according to $C$. Jung with the selected earlier personal qualities that cause the communication difficulties of the preschoolers as subjects of the collaborative thinking activity. As the result of the study we have identified several personality traits: aggression, proneness to conflict, negativism, asociality, isolation. The intensity of these qualities in the interaction subjects causes the communication difficulties (Tsukanova E.V., 1985). In addition, we identified several personal and other qualities specific to a particular type of the drawing. It should be noted that for the same preschooler may be characteristic several personal qualities that cause the communication difficulties.

The analysis showed that aggression and isolation are more common for the preschoolers with the introverted feeling personality type. As for the people with this personality type is characteristic the reserved character, abstrusity for the other people, which is likely to contribute in general to the development of the isolation and aggression, when others are trying to intrude in the personal space of the introverted feeling type.

Proneness to conflict is not expressed in all personality types, except for the preschoolers - introverted thinking types. Introverted thinking types are characterized by the focus on the theoretical knowledge, but they are also characterized by the "free" treatment of the facts which they prefer to see through the prism of their own ideas. In this 
regard, the confrontation situations can arise at the interaction of the subjective viewpoints on one or another fact that lead to the conflict.

Negativism is more common for the preschoolers with the "extraverted thinking" personality type. For the extroverted thinking type is characteristic the rationality and a tendency to synthesize isolated ideas to a certain formula. Apparently, this can lead to the opposition of one's own opinion to the opinions of others, which is typical for children's negativism.

Asociality dominates in the preschoolers with the extraverted intuition types. It is significant that for the latter is characteristic a desire to create their own values, morals, concepts of existence. E.S. Romanova, O.F. Potemkina, describing this personality type, say: "It has its own morality at odds with the generally accepted one" (Romanova E.S., Potemkina O.F., 1991. P. 123). In this regard, the dominance of the asociality, complicating the interpersonal communication, is predictable and logical in the extraverted intuition personality structure.

It should be noted that the comparative analysis showed the presence of the personal qualities and other characteristics that are more common for the different personality types of the preschoolers. So, for the extraverted intuition type is characteristic anxiety (28.6\%), and a strong need for the communication (35.7 \%). Introverted thinking type has a strong need for the communication (35.5\%), along with the issues in the communication, with the issues in establishing contact (35.5\%). Introverted feeling type shows the high stress (70 \%). Extraverted thinking type shows the demonstrativeness (18.8\%) and impulsivity (18.8\%).

Analysis of the personal qualities that influence the communication processes during the collaborative problem solving revealed certain personality profiles specific for each personality type of the preschooler: for the extraverted intuition type is characteristic: strong need for the communication (35.7\%), anxiety (28.6\%), aggression (21\%), negativism and asociality (14.3\%); introverted thinking type has the strong need for the communication (35.5\%), issues in communication and in establishing contact (35.5\%), isolation (16.1\%), aggression (12.9\%); introverted feeling type shows the stress (70\%), aggression (40\%), isolation (30\%), negativism and asociality (10\%); extraverted thinking type shows negativism (25\%), demonstrativeness and impulsivity (18.8\%).

\section{Conclusions}

Thus, our analysis has allowed to create the personality profiles of the preschoolers, including the personal qualities that affect the interpersonal communication. In this sense, all personality types include certain qualities that may complicate the communication process of the preschoolers. However, the presence of certain qualities, that complicate the communication, is not an indication of the issues in the interaction during the collaborative solving of the intellectual tasks. This may be indicative of the fact that $55.2 \%$ of the study dyads have medium, high and the highest index of the communication intensity (Belousova A.K., 2002), which is an indicator of the communication effectiveness in the collaborative thinking activity. For example, the presence of a strong need for the communication among many preschoolers can substantially compensate the negative impact on the group by the certain personal qualities of the preschoolers.

\section{References}

Belousova, A.K., Pavlova, T.V. (2013). Characteristics of preschoolers' dialogue in collaborative thinking activity // Educational Psychology. № 1. Pp. 13-19.

Pavlova, T.V. (2010). Cognitive activity of preschoolers in collaborative thinking activity // Current studies of social issues. - No 4. - Pp. $139-145$.

Pavlova, T.V. (2010). Functions distribution in preschoolers' collaborative thinking activity structure // Southern Federal University Proceedings. Educational sciences, No 7, pp.103-110.

Belousova, A.K., Dautov, D.F. (2009). Mutual interaction of partners in collaborative thinking activity in practice of teaching / A.K. Belousova, D.F. Dautov // SFU Proceedings. Educational sciences. Rostov-on-Don: TTI SFU Publishing House. No 9. Pp.117127.

Belousova, A.K. (2002). Collaborative thinking activity self-organization / A.K. Belousova. Rostov-on-Don: RSTTU Publishing House. 360 pp.

Oblasova, O.V. (2002). Role functions and terms of their acceptance by collaborative thinking activity participants / O.V. Oblasova: PhD thesis, Barnaul. $75 \mathrm{pp}$.

Romanova, E.S., Potemkina, O.F. (1992). Graphical methods in psychological diagnostics / E.S. Romanova, O.F. Potemkina. Moscow: Didakt Publishing House. 256 pp.

Brushlinsky, A.V., Polikarpov, V.A. (1990). Thinking and communication / A.V. Brushlinsky, V.A. Polikarpov. Minsk: University Publishing House. - $214 \mathrm{pp}$. 
Khusainova, N.R. (1989). Personal conditionality of sense formation types in solving intellectual task / N.R. Khusainova: PhD thesis. Moscow. 207 pp.

Mastvilisker, E.I. (1989). Individual communication style in collaborative play and subjective activity / E.I. Mastvilisker // Psychology issues. No 3. Pp. 63-70.

Tsukanova, E.V. (1985). Psychological difficulties of interpersonal communication / E.V. Tsukanova. Kiev.: Publishing Association "Visha School". 160 pp.

Kuchynsky, G.M. (1981). Dialogue in process of collaborative solving of intellectual tasks / G.M. Kuchynsky / Communication issue in psychology / Ed. by B.F. Lomov. Moscow. Pp. 92-120. 